\title{
A pilot study evaluating the factors associated with psychological distress of school teachers in Kagawa Prefecture, Japan
}

\author{
Yoshikazu Miyamae ${ }^{1^{*}}$, Nobuyuki Miyatake ${ }^{2}$, Junko Miyamae $^{3}$, Takeshi Suzue $^{4}$, \\ Noriko Sakano ${ }^{2}$, Taichi Nagatomi ${ }^{5}$, Wataru Shiraki ${ }^{6}$, Tomohiro Hirao ${ }^{7}$ \\ ${ }^{1}$ Center for Educational Research and Teacher Development, Faculty of Education, Kagawa University, Kagawa, Japan; \\ *Corresponding Author: miyamae@ed.kagawa-u.ac.jp \\ ${ }^{2}$ Department of Hygiene, Faculty of Medicine, Kagawa University, Kagawa, Japan \\ ${ }^{3}$ Faculty of Education, Kagawa University, Kagawa, Japan \\ ${ }^{4}$ Department of Nursing, Faculty of Nursing, Sanyo Gakuen University, Okayama, Japan \\ ${ }^{5}$ Institute of Research Partnership Center for Social Collaboration and Intellectual Property, Kagawa University, Kagawa, Japan \\ ${ }^{6}$ Department of Reliability-Based Information Systems Engineering, Faculty of Engineering, Kagawa University, Kagawa, Japan \\ ${ }^{7}$ Department of Public Health, Faculty of Medicine, Kagawa University, Kagawa, Japan
}

Received 10 March 2013; revised 21 April 2013; accepted 14 May 2013

Copyright (C) 2013 Yoshikazu Miyamae et al. This is an open access article distributed under the Creative Commons Attribution License, which permits unrestricted use, distribution, and reproduction in any medium, provided the original work is properly cited.

\begin{abstract}
Objective: We investigated the psychological distress of school teachers using a 6-item instrument (the K6) in Kagawa prefecture, Japan. Methods: A total of 670 school teachers (328 men and 342 women) were analyzed in this crosssectional investigation study. The association between psychological distress and clinical factors was evaluated by using the $\mathrm{K} 6$ instrument, with psychological distress defined as 13 or more points out of a total of 24 points. Results: A total of 55 teachers $(8.2 \%)$ were classified as having psychological distress. No significant relationships between the $\mathrm{K} 6$ score and sex, age, duration of experience as a teacher, school grade and title were noted. The $\mathrm{K} 6$ score in teachers with consciousness of suicide among students was higher than that without, but not at a significant level. Conclusion: Some teachers were defined as having psychological distress in $\mathrm{Ka}-$ gawa prefecture, Japan. However, no relevant effects of basic characteristics such as age and sex on psychological distress were recognized.
\end{abstract}

Keywords: Psychological Distress; K6; School Teacher; Kagawa Prefecture; Japan

\section{INTRODUCTION}

Psychological disorders and their related problems have become a public health challenge in Japan and about thirty thousand people are reported to commit suicide annually [1]. According to data on school teachers in Japan, over five thousand school teachers a year $(0.6 \%)$ were absent from school due to mental disease over a four year period [2]. The average working hours, especially overtime work, of school teachers are relatively long. In addition, the level of some of their working hours is extremely high [3,4]. Therefore, appropriate provision to address the psychological distress of school teachers is urgently required, and recommendations based on their actual circumstances have been presented by the Ministry of Education, Culture, Sports, Science and Technology, Japan [5]. In some studies in the literature, the mental health of school teachers has been reported [6-12]. However, the link between psychological distress of school teachers by using the $\mathrm{K} 6$ and clinical factors in Japan has not been fully discussed.

In this study, we evaluated the psychological distress of school teachers in Kagawa prefecture, Japan using the $\mathrm{K} 6$ scale and its relation to clinical factors.

\section{SUBJECTS AND METHODS}

\subsection{Subjects}

We used data on 670 respondents (73.3\%) among 914 school teachers ( 8 primary schools, 9 junior high schools and 9 high schools) in Kagawa prefecture, Japan, who met the following criteria: 1) they had completely answered the questionnaires (clinical characteristics and the 
K6) from Nov 2010 to Mar 2011; and 2) they provided informed consent (Table 1).

Ethical approval for the study was obtained from the Ethical Committee of Faculty of Medicine, Kagawa University, Japan.

\subsection{Psychological Distress}

The K6 was used as an indicator of psychological distress [13]. The 6 questions were as follows: "Over the last month, how often did you feel: 1) nervous, 2) hopeless, 3) restless or fidgety, 4) so sad that nothing could cheer you up, 5) that everything was an effort, 6) worthless?" Participants were asked to respond by choosing "all of the time" (4 points), "most of the time" (3 points), "some of the time" (2 points), "a little of the time" (1 point), and "none of the time" ( 0 points). Therefore, the total point score ranged from 0 to 24 . The K6 has been developed using modern psychometric theory and has been shown to be superior to some existing scales in terms of brevity and psychometric properties [14-16]. A Japanese version of the K6 has been developed using the standard back-translation method, and has been validated [13]. As suggested by Kessler et al. [16], we classified participants with scores of 13 points or more as having psychological distress.

\subsection{Measurement of Clinical Variables}

The questionnaires for school teachers consisted of the following details in sequence: sex, age, duration of

Table 1. Clinical characteristics of enrolled teachers in Kagawa prefecture, Japan.

\begin{tabular}{cc}
\hline Number of teachers & 670 \\
\hline Men/Women & $328(49.0 \%) / 342(51.0 \%)$ \\
Age & $44.8 \pm 9.4^{\mathrm{a}}$ \\
Duration of experience as a & $20.7 \pm 9.9$ \\
school teacher & \\
School grade ${ }^{\mathrm{b}}$ & \\
Primary school & 8 schools, 198 teachers \\
Junior high school & 9 schools, 194 teachers \\
High school & 9 schools, 270 teachers \\
Title & 13 \\
Principal & 34 \\
Vice-principal & 591 \\
Teacher & 20 \\
School nurse & \\
Others & \\
\hline
\end{tabular}

${ }^{\mathrm{a}}$ Data were expressed as mean $\pm \mathrm{SD} ;{ }^{\mathrm{b}} 8$ teachers were excluded because they belonged to both junior high and high schools. experience as a school teacher, school grade and title. In addition, we evaluated the consciousness of suicide among students, anxiety about preventing suicide, and participation in programs for mental health by asking the following questions. 1) Do you ever worry about suicide of children in your daily work as a teacher? 2) If you had to do something individually to prevent the suicide of a child (children) in your daily work as a teacher, how much anxiety would you feel? 3) Have you ever participated in a training/education program about the mental health of teachers?

\subsection{Statistical analysis}

Data are expressed as the mean \pm standard deviation (SD) values. Statistical analysis was performed using the unpaired $t$-test, ANOVA and Scheffe's F test. Simple correlation analysis was also performed to test for the significance of the linear relationship among continuous variables, where $p<0.05$ was considered to be statistically significant.

\section{RESULTS}

The total K6 score was $5.6 \pm 4.7$, and the details were as follows: 1 ) nervous: $1.3 \pm 1.1 ; 2$ ) hopeless: $0.6 \pm 0.9$; 3) restless or fidgety: $1.0 \pm 1.0 ; 4)$ so sad that nothing could cheer you up: $1.0 \pm 1.0 ; 5)$ that everything was an effort: $1.0 \pm 1.0 ; 6$ ) worthless: $0.7 \pm 0.9$. A total of 55 school teachers $(8.2 \%)$ were defined as having psychological distress. We investigated the relation between the K6 score and sex, age, duration of experience as a school teacher, school grade and title. There were no significant relationships between the K6 score and age $(r=-0.004$, $p=0.910)$, duration of experience as a school teacher $(\mathrm{r}=$ $0.031, p=0.425$ ), or other basic characteristics (Table 2).

Next, we also evaluated the factors, i.e. consciousness of suicide, anxiety about preventing suicide, and participation in programs for mental health. The K6 score in subjects with consciousness of suicide (most of the time) was higher than that without (a little of the time), but not at a significant level. No effect of anxiety about preventing suicide and participation in programs for mental health on psychological distress was recognized (Table 3).

\section{DISCUSSION}

We evaluated the psychological distress of school teachers using the K6 instrument in Kagawa prefecture, Japan.

In community-dwelling people aged 40 years or older living in Japan, Kuriyama et al. reported that the rate of subjects with psychological distress was $6.7 \%$ by using the K6 [17]. We also showed that the rates of medical doctors and public health nurses with psychological distress by using the K6 were $6.0 \%$ and $5.9 \%$ in Kagawa 
Table 2. Relationship between the K6 score and basic characteristics of school teachers in Kagawa prefecture, Japan.

\begin{tabular}{ccc}
\hline Factors & K6 score & $p$ \\
\hline Sex & & \\
Men & $5.7 \pm 4.7^{\mathrm{a}}$ & 0.347 \\
Women & $5.4 \pm 4.7$ & \\
School grade & & \\
Primary school & $5.4 \pm 4.8$ & 0.714 \\
Junior high school & $5.7 \pm 4.6$ & \\
High school & $5.6 \pm 4.8$ & \\
Title & \\
Principal & $2.8 \pm 3.0$ & 0.261 \\
Vice-principal & $5.9 \pm 4.0$ & \\
Teacher & $5.6 \pm 4.8$ & \\
School nurse & $5.6 \pm 3.8$ & \\
Others & $6.6 \pm 5.5$ &
\end{tabular}

${ }^{a}$ Data were expressed as mean $\pm \mathrm{SD} ;{ }^{\mathrm{b}} 8$ teachers were excluded because they belonged to both junior high and high schools.

Table 3. Relationship between the K6 score and clinical factors of school teachers in Kagawa prefecture, Japan.

\begin{tabular}{cccc}
\hline Factors & $\begin{array}{c}\text { Number of } \\
\text { teachers }\end{array}$ & K6 score & $p$ \\
\hline Consciousness of suicide among students & & \\
Most of the time & 76 & $6.8 \pm 5.2^{\mathrm{a}}$ & 0.096 \\
Some of the time & 201 & $5.4 \pm 4.9$ & \\
A little of the time & 19 & $4.8 \pm 6.1$ & \\
None of the time & 372 & $5.9 \pm 5.0$ & $0.116^{\mathrm{b}}$ \\
Anxiety about preventing suicide & & & \\
Most of the time & 275 & $5.1 \pm 4.4$ & \\
Some of the time & 21 & $6.0 \pm 4.0$ & \\
A little of the time & 2 & $5.0 \pm 5.7$ & \\
None of the time & 207 & $5.4 \pm 4.4$ & 0.507 \\
Participation in programs for mental health & & \\
Yes & 463 & $5.6 \pm 4.9$ & \\
No & 207 &
\end{tabular}

${ }^{\mathrm{a}}$ Data were expressed as mean $\pm \mathrm{SD} ;{ }^{\mathrm{b}} 2$ teachers were excluded because of a small samples size.

prefecture, Japan [18,19]. Fushimi et al. reported that $10.8 \%$ of Japanese employees had high psychological distress in Akita prefecture, Japan [20]. In this study, a total of $8.2 \%$ of school teachers were defined as having psychological distress in Kagawa prefecture, Japan. Therefore, the rate of school teachers with psychological distress was higher than that of Japanese general people, medical doctors and public health nurses [17-19], and similar to that of Japanese employees [20]. According to data on the mental health of school teachers in Japan, the proportion of teachers with minor psychiatric disorders was higher than that among civil servants [6] by using the Japanese version of the General Health Questionnaire (GHQ) [21]. The rate of burnout status in school teachers was higher than that in medical doctors and nurses by using the Japanese version of the Burnout Measure [7]. These previous studies and our studies indicate that school teachers may have more mental health problems than other workers.

Factors associated with the mental health of school teachers have been reported in the literature. There were differences in burnout status between the two sexes in primary and junior high school teachers [8-10]. Duration of experience as a school teacher was associated with burnout status [11]. Teachers at junior high schools had higher burnout status compared with those at primary schools [9]. Principal and vice-principal teachers also had lower burnout status $[9,10]$. However, in this study, we could not find any significant effect of basic characteristics on psychological distress by using the K6 in school teachers in Kagawa prefecture, Japan. Misawa reported that duration of experience as a school teacher was not associated with burnout status [8]. ITO did not recognize any sex differences in burnout status, either [11]. In addition, clinical factors i.e. consciousness of suicide, anxiety about preventing suicide and participation in programs for mental health were not associated with psychological distress in our study. Ochiai recommended that not only individual factors, but also sociocultural factors, were important when evaluating burnout in school teachers [12]. Taken together, many complicated factors may be associated with psychological distress in school teachers. Therefore, to prevent and improve the psychological distress of school teachers, we should more carefully consider their socio-cultural situations.

Potential limitations remain in this study. First, our study was cross-sectional and not longitudinal. Second, the 26 schools in which we evaluated psychological distress were not randomly selected. In addition, 670 school teachers among 914 teachers in our study voluntarily underwent measurements in Kagawa prefecture, Japan, so they were more likely to be health-conscious compared with other teachers. Third, we could not investigate other confounding factors such as alcohol drinking, family mental history and socio-cultural factors in this study. Therefore, ongoing longitudinal investigation studies are required to prove such links. 


\section{ACKNOWLEDGEMENTS}

This research was supported in part by Kagawa Prefecture, Japan.

\section{REFERENCES}

[1] Cabinet Office, Government of Japan (2012) Changes in numbers of subjects due to suicide. http://www8.cao.go.jp/jisatsutaisaku/whitepaper/w-2012/ $\mathrm{pdf} /$ honbun/pdf/p2-4.pdf

[2] Ministry of Education, Culture, Sports, Science and Technology, Japan (2012) Changes in numbers of absentees due to mental disease among school teachers. http://www.mext.go.jp/component/a_menu/education/det ail/_ icsFiles/afieldfile/2012/12/26/1329088_01.pdf

[3] The University of Tokyo (2007) Evaluation of working in primary and junior high school teachers. http://benesse.jp/berd/center/open/report/kyouinjittai/200 6/index sc.html

[4] Benesse Educational Research \& Development Center, Japan (2007) Evaluation of working in high school teachers.

http://benesse.jp/berd/center/open/report/kyouinjittai/200 6/index kou.html

[5] Ministry of Education, Culture, Sports, Science and Technology, Japan (2013) Strategy for mental health in school teachers (final report).

http://www.mext.go.jp/component/b menu/shingi/toushin / icsFiles/afieldfile/2013/03/29/1332655 03.pdf

[6] Nagai, M., Tsuchiya, K.J., Toulopoulou, T. and Takei, N. (2007) Poor mental health associated with job dissatisfaction among school teachers in Japan. Journal of Occupational Health, 49, 515-522. doi:10.1539/joh.49.515

[7] Munakata, T., Inaoka, F., Takahashi, T. and Kawano, M. (1988) Burn out syndrome: Mental health in doctors, nurses, and teachers. Kongou Shuppan, Tokyo.

[8] Misawa, M. (2012) Mental health and burnout in primary school and junior high school teachers: Investigation into their daily-lives. Bulletin of graduate studies/Hosei University, 68, 97-107.

[9] Miyashita, T., Mori, K., Nishimura, A. and Kitazima, M. (2011) The present condition of burnout in elementary school and junior high school teacher: Through three investigations. Bulletin of Joetsu University of Education, 30, 143-152.

[10] Kudomi, Y. (1995) Burnout and the devoted image of Japanese teachers: Teachers' culture in Japan (part 5). Hitotsubashi University research series. Social Sciences, 34, 3-42.

[11] Ito, M. (2000) Burnout among teachers: Teaching experience and type of teacher. Japanese Journal of Educational Psychology, 48, 12-20.

[12] Ochiai, M. (2003) Teacher burnout: A review. Japanese
Journal of Educational Psychology, 51, 351-364.

[13] Furukawa, T.A., Kawakami, N., Saitoh, M., Ono, Y., Nakane, Y., Nakamura, Y., Tachimori, H., Iwata, N., Uda, H., Nakane, H., Watanabe, M., Naganuma, Y., Hata, Y., Kobayashi, M., Miyake, Y., Takeshima, T. and Kikkawa, T. (2008) The performance of the Japanese version of the K6 and K10 in the World Mental Health Survey Japan. International Journal of Methods in Psychiatric Research, 17, 152-158. doi: $10.1002 / \mathrm{mpr} .257$

[14] Kessler, R.C., Andrews, G., Colpe, L.J., Hiripi, E., Mroczek, D.K., Normand, S.-L.T., Walters, E.E. and Zaslavsky, A.M. (2002) Short screening scales to monitor population prevalences and trends in non-specific psychological distress. Psychological Medicine, 32, 959-976. doi:10.1017/S0033291702006074

[15] Furukawa, T.A., Kessler, R.C., Slade, T. and Andrews, G. (2003) The performance of the K6 and K10 screening scales for psychological distress in the Australian National Survey of Mental Health and Well-Being. Psychological Medicine, 33, 357-362. doi:10.1017/S0033291702006700

[16] Kessler, R.C., Barker, P.R., Colpe, L.J., Epstein, J.F., Gfroerer, J.C., Hiripi, E., Howes, M.J., Normand, S.-L.T., Manderscheid, R.W., Walters, E.E. and Zaslavsky, A.M. (2003) Screening for serious mental illness in the general population. Archives of General Psychiatry, 60, 184-189. doi:10.1001/archpsyc.60.2.184

[17] Kuriyama, S., Nakaya, N., Ohmori-Matsuda, K., Shimazu, T., Kikuchi, N., Kakizaki, M., Sone, T., Sato, F., Nagai, M., Sugawara, Y., Akhter, M., Higashiguchi, M., Fukuchi, N., Takahashi, H., Hozawa, A. and Tsuji, I. (2009) Factors associated with psychological distress in a communitydwelling Japanese population: the Ohsaki Cohort 2006 Study. Journal of Epidemiology, 19, 294-302. doi:10.2188/jea.JE20080076

[18] Suzue, T., Sakano, N., Miyamae, Y., Yoda, T., Yoshioka, A., Nagatomi, T., Shiraki, W. and Hirao, T. (2011) Factors associated with psychological distress of medical doctor in Kagawa prefecture, Japan: a pilot study. Health, 3, 748751. doi:10.4236/health.2011.312124

[19] Sakano, N., Suzue, T., Miyatake, N., Miyamae, Y., Nagatomi, T., Yoda, T., Yoshioka, A., Shiraki, W. and Hirao T. (2012) Factors associated with psychological distress of public health nurse in Kagawa prefecture, Japan: A pilot study. Open Journal of Nursing, 2, 23-26. doi:10.4236/ojn.2012.21004

[20] Fushimi, M., Saito, S., Shimizu, T., Kudo, Y., Seki, M. and Murata, K. (2012) Prevalence of psychological distress, as measured by the Kessler 6 (K6), and related factors in Japanese employees. Community Mental Health Journal, 48, 328-335.

[21] Nakagawa, Y. and Daibo, I. (1985) The Japanese version; General Health Questionnaire. Nihon Bunka Kagakusha, Tokyo. 